\title{
Características de carcaça de cordeiros terminados em confinamento, com dietas contendo diferentes níveis protéicos ${ }^{1}$
}

\author{
Carcass characteristics of lambs finished in drylot with diets contend \\ different protein levels
}

\author{
Marilice Zundt ${ }^{2}$ Francisco de Assis Fonseca de Macedo ${ }^{3}$ Elias Nunes Martins ${ }^{4}$ \\ Alexandre Agostinho Mexia $^{2}$ Leonardo Martin Nieto ${ }^{5}$ Sandra Mari Yamamoto $^{2}$ \\ Rosa Maria Gomes de Macedo ${ }^{6}$
}

\section{RESUMO}

Trinta e dois cordeiros (1/ Texel + 1/4 Bergamácia + 1/4 Corriedale), 16 machos inteir ${ }^{2}{ }^{2}$ e 16 fêmeas, foram alimentados durante 71 dias com dietas isoenergéticas (72\% NDT), variando os niveis protéicos (12, 16, 20 e $24 \%$ PB) em baias individuais, com avaliação de carcaça após abate. $O$ rendimento verdadeiro médio da carcaça foi $54 \%$, enquanto o rendimento comercial médio foi $48 \%$. Verificou-se que os níveis protéicos entre 12 e 24\% não afetaram o peso da carcaça quente e fria; o rendimento comercial da carcaça, o indice de compacidade da carcaça e do pernil, bem como a condição corporal, conformação, cobertura de gordura, consistência da gordura, cor da carne, espessura de gordura e deposição de gordura. Os animais terminados com dietas com $12 \%$ de proteina bruta foram os que apresentaram maior rendimento verdadeiro de carcaça.

Palavras-chave: características qualitativas, características quantitativas, ovinos, proteina, rendimentos de carcaça.

\section{ABSTRACT}

Thirty two tricross lambs were finished (1/2 Texel + $1 / 4$ Bergamácia $+1 / 4$ Corriedale), 16 males and 16 females, were fed for 71 days, with isoenergetic diets (72\% TDN), but with different protein levels (12,16,20 and 24\% PB) and kept indoors in individual pens. The carcass were evaluated after slaughter. The average net carcass yield was 54\%, while the average commercial carcass yield was $48 \%$. It was verified that protein levels between 12 and 24\% did not affect hot and cold carcass weights; commercial carcass yield, indexes of compactness of the carcass, and ham, as well as the body condition, carcass conformation, fat covering, fat consistency, meat color, fat thickness and fat deposition. The animals finished with $12 \%$ crude protein in the diet showed the highest carcass yield.

Key words: carcass yield, protein, qualitative carcass characteristics, quantitative carcass characteristics, sheep.

\section{INTRODUÇÃO}

No sistema de produção de carne, as características qualitativas e quantitativas da carcaça são de fundamental importância (SILVA \& PIRES, 2000). Segundo SAINZ (1996), a composição e a qualidade da carcaça são características de igual importância para determinar a aceitação de novas raças e seus cruzamentos. JORGE et al. (1999) relataram que o conhecimento das características da carcaça é de suma importância para complementar a avaliação do desempenho animal. Em relação ao rendimento da carcaça, as fêmeas apresentaram um maior rendimento que os machos isso se deve à maior precocidade e, portanto, ao superior grau de gordura.

\footnotetext{
${ }^{1}$ Parte da dissertação de Mestrado do primeiro autor. Projeto financiado pela CAPES. Universidade Estadual de Maringá (UEM), PR ${ }^{2}$ Zootecnistas, alunos do curso de pós-graduação em Zootecnia,UEM. Correspondência para: Av. Tiradentes, n. 84, apto. 124, Zona 01,87013-260, Maringá, PR Email:mzundt@uol.com.br. Autor para correspondência.

${ }^{3}$ Zootecnista, Professor do Departamento de Zootecnia, UEM.

${ }^{4}$ Engenheiro Agronômo, Professor do Departamento de Zootecnia, UEM

${ }^{5}$ Geneticista, Doutor em Zotecnia, UEM.

${ }^{6}$ Biologia, Professora do Departamento de Zootecnia, UEM.
} 
As medidas realizadas na carcaça são de fundamental importância, pois permitem comparações entre tipos raciais, pesos e idades de abate, sistemas de alimentação e, também, o estabelecimento de correlações com outras medidas ou com os tecidos constituintes da carcaça, possibilitando a estimação de suas características físicas, evitando, dessa forma, o oneroso processo de dissecação de carcaça (SILVA \& PIRES, 2000). Dentre essas medidas, destaca-se a condição corporal. A avaliação subjetiva realizada nos ovinos vivos indica a proporção entre as massas muscular e adiposa, em relação ao osso (JARRIGE, 1988), orientando a melhor época de abate, com a finalidade de se obter carcaças com bom acabamento, enquanto a conformação, por sua vez, é um critério básico utilizado para determinar a qualidade da carcaça (qualitativo e, ao mesmo tempo, quantitativo), porque é susceptível de se medir e quantificar.

O teor de tecido adiposo na carcaça ovina é fator determinante de sua qualidade. A gordura é, de todos os componentes da carcaça, aquele que apresenta maiores variações qualitativas e quantitativas e, assim, de acordo com as preferências dos consumidores de diferentes países, pode ser um fator depreciativo da carcaça (TEIXEIRA et al., 1992). Um outro fator importante e medido objetivamente é a área de olho de lombo, considerado de grande valor na predição da quantidade de músculo da carcaça, já que este constitui a carne magra, comestível e disponível para venda. O Longissimus dorsis é o mais indicado, pois, além do amadurecimento tardio, é de fácil mensuração (SAINZ, 1996).

O teor de proteína na carcaça dos animais domésticos diminui com o aumento da idade, enquanto a quantidade de lipídio aumenta. Logo, deve-se procurar abater ovinos jovens, desde que apresentem pesos de carcaça compatíveis com a exigência do consumidor (MACEDO, 1998).

Diante do exposto, o presente trabalho teve como objetivo comparar as características da carcaças de cordeiros terminados em confinamento, recebendo dietas com diferentes níveis protéicos.

\section{MATERIAL E MÉTODOS}

O experimento foi conduzido no setor de Ovinocultura na Fazenda Experimental de Iguatemi, pertencente à Universidade Estadual de Maringá (UEM). Foram utilizados 32 cordeiros "tricross" ( $1 / 2$ Texel +1/4 Bergamácia + 1/4 Corriedale), com idade média de 5 meses. Os animais foram identificados, pesados e distribuídos nos quatro tratamentos, permanecendo em baias individuais, cobertas, com piso ripado e suspenso, recebendo água à vontade, durante todo o período experimental. Cada tratamento continha 4 machos e 4 fêmeas, que receberam dietas isoenergéticas (72\% de NDT), variando os níveis de proteína de $12,16,20$ e $24 \%$.

A composição das dietas utilizadas em cada tratamento estão especificadas na tabela 1 . O experimento teve duração total de 71 dias, precedido de um período de adaptação de 10 dias. Ao final do período experimental os animais permaneceram exclusivamente sob dieta hídrica, durante 18 horas. Previamente ao sacrifício, determinou-se a condição corporal, conferindo-se nota de 1,00 para pior e 5,00, para a melhor (OSÓRIO et al., 1992).Os animais foram abatidos com média de $40 \mathrm{~kg}$ de peso vivo. Após o sacrifício, o aparelho gastrintestinal foi esvaziado, para obtenção do peso corporal vazio, visando determinar o rendimento verdadeiro ou biológico, que é a relação entre o peso da carcaça quente e aquela variável (SAÑUDO \& SIERRA, 1986).

Terminada a evisceração, as carcaças foram pesadas (peso da carcaça quente), e transferidas para uma câmara frigorífica, a uma temperatura de $4^{\circ} \mathrm{C}$, onde permaneceram por 24 horas. Ficaram penduradas pelos tendões em gancho, distanciadas em $17 \mathrm{~cm}$. Ao final desse período, pesou-se a carcaça fria, calculando-se, assim, o rendimento comercial (relação entre o peso da carcaça fria e o peso vivo ao abate). A seguir, foram realizadas as seguintes mensurações: comprimento do pernil; comprimento interno da carcaça; largura da garupa, afim de se determinar os índices de

Tabela 1 - Composição química e percentual das rações experimentais (\% MS)

\begin{tabular}{lcccc}
\hline & \multicolumn{4}{c}{ Nível Protéico } \\
\cline { 2 - 5 } Nutrientes & $12 \% \mathrm{~PB}$ & $16 \% \mathrm{~PB}$ & $20 \% \mathrm{~PB}$ & $24 \% \mathrm{~PB}$ \\
\hline Matéria Seca (MS) & 98,50 & 98,20 & 98,40 & 98,10 \\
Proteína bruta (PB) & 12,54 & 16,77 & 20,44 & 24,45 \\
Extrato etéreo (EE) & 2,94 & 2,83 & 2,91 & 2,87 \\
Fibra detergente neutro (FDN) & 36,14 & 29,84 & 29,27 & 37,10 \\
Fibra detergente ácido (FDA) & 14,52 & 13,34 & 14,23 & 17,94 \\
Matéria mineral (MM) & 4,98 & 7,43 & 7,28 & 5,38 \\
Cálcio & 0,92 & 1,46 & 1,35 & 1,02 \\
Fósforo & 0,7 & 1,0 & 0,91 & 0,70 \\
Ingredientes & & & & \\
Milho & 59,71 & 48,41 & 36,90 & 25,38 \\
Farelo de soja & 7,17 & 18,03 & 28,97 & 39,89 \\
Feno de aveia & 30,00 & 30,00 & 30,00 & 30,00 \\
Fosfato bicálcico & 2,35 & 2,33 & 2,03 & 1,87 \\
Calcário & 0,77 & 0,77 & 0,77 & 0,77 \\
Óleo Vegetal & & 0,56 & 1,32 & 2,09 \\
\hline
\end{tabular}


compacidade da carcaça (peso da carcaça fria dividido pelo comprimento interno da carcaça) e de compacidade da pernil (largura da garupa dividida pelo comprimento do pernil) de acordo com metodologia proposta por SAÑUDO \& SIERRA, 1986.

Foi realizada a avaliação subjetiva das carcaças, segundo metodologia de COLOMERROCHER (1988), considerando-se as seguintes variáveis: cobertura de gordura $(1,00$, para a excessivamente magra e 5,00, para excessivamente gorda); grau de conformação, sendo os valores 1,00 atribuído à conformação muito pobre, e 5,00, para excelente. Para consistência da gordura, utilizou-se 1,00 para firme e 3,00 para mole e cor da carne, 1,00 para rosa e 3,00 para roxa.No Longissimus dorsi, foi determinada a área de olho de lombo e medida a espessura da gordura de cobertura.

Ao início e final do período experimental, foram coletadas amostras do músculo Semitendinosus (biopsia), para determinação do ganho em proteína e lipídios. As amostras do músculo foram encaminhadas para análise dos teores de proteína total (método semimicro Kjedahl) e lipídio segundo FOLCH et al. (1957), ao Laboratório do Departamento de Química da UEM. De posse dessas análises, foram calculadas a quantidade de proteína depositada no músculo, por meio da diferença entre a proteína inicialmente depositada e a proteína depositada no músculo, ao final do período experimental.

A análise estatística para as medidas objetivas foi realizada por meio de análise de variância, utilizando o Sistema de Análises Estatísticas e Genéticas, SAEG (EUCLYDES, 1993), de acordo com o seguinte modelo:

$Y_{i j k}=\mu+S_{i}+N_{j}+S N_{i j}+b_{1}\left(P I_{i j k}-\overline{P I}\right)^{2}+e_{i j k}$, sendo consideradas as variáveis sexo; nível de proteína bruta e a interação entre ambas e o peso vivo inicial como covariável. Foi usada a metodologia de modelos lineares generalizados, por meio do software GLIM 4.0, para as análise das medidas subjetivas da carcaça, visto que essas variáveis não apresentaram distribuição normal como detectado pelo Teste de Lilliefors. Assim, para as análises de deviance (McCULLOCH \& SEARLE, 2001), a distribuição que se apresentou mais adequada foi a Gama, com função de ligação identidade.

\section{RESULTADOS E DISCUSSÃO}

As médias e erros-padrão para peso da carcaça quente, peso da carcaça fria, rendimento comercial da carcaça, rendimento verdadeiro da carcaça, índice de compacidade da carcaça e do pernil, condição corporal, conformação, cobertura de gordura, consistência da gordura, cor da carne, área de olho de lombo e espessura de gordura, de acordo com os níveis protéicos na dieta e sexo, encontram-se na tabela 2.

A análise de variância não revelou diferença significativa para peso da carcaça quente e fria, indicando que não houve efeito $(\mathrm{P}>0,05)$ dos níveis protéicos. Não foi observado efeito $(\mathrm{P}>0,05)$ de sexo para estas variáveis. A média geral para peso da carcaça quente, para os cordeiros machos, foi de $18,5 \mathrm{~kg}$ e para as fêmeas, $18,8 \mathrm{~kg}$. Para peso da carcaça fria a média geral para machos foi de $17,9 \mathrm{~kg}$ e para fêmeas de $18,07 \mathrm{~kg}$.

A média geral para rendimento comercial da carcaça, foi de 48,3\%. A análise estatística mostrou que esta variável não sofreu efeito $(\mathrm{P}>0,05)$ dos níveis de proteína. As médias para rendimento comercial da carcaça, encontradas por FERNANDES (1994), foram de $37,71 \%$ para cordeiros Corriedale e, $38,21 \%$, para cordeiros mestiços Ile de France x Corriedale, terminados em confinamento, recebendo dieta com $15 \%$ de $\mathrm{PB}$ e $70 \%$ de NDT, abatidos com 30 a $32 \mathrm{~kg}$ de peso vivo. MACEDO (1998) encontrou valores de 42,59\% para animais cruzados, terminados em confinamento, recebendo dieta contendo $18 \%$ PB e $72 \%$ NDT. Não houve efeito $(\mathrm{P}>0,05)$ de sexo para rendimento comercial da carcaça.

O rendimento verdadeiro ou biológico é mais preciso, pois é eliminado o conteúdo digestivo em seu cálculo. Verificou-se redução linear $(\mathrm{P}=0,052)$ nos valores de rendimento verdadeiro, com a elevação dos níveis de proteína. A equação de regressão ajustada, para rendimento verdadeiro $(\hat{Y}=0,5752$ 0,0017x), mostra redução de aproximadamente 0,0017\% para cada $1 \%$ de aumento no nível de proteína. Os valores de rendimento verdadeiro, de acordo com a equação acima, para os níveis de 12, 16, 20 e 24\% de PB são, respectivamente: 55,46; 54,79; 54,12 e 53,45\%

A análise de variância mostrou efeito de sexo $(\mathrm{P}=0,07)$ sobre o rendimento verdadeiro. A média para rendimento verdadeiro, encontrada por MACEDO (1998), foi de 49,07\%, para animais terminados em confinamento, recebendo dieta com $18 \%$ de $\mathrm{PB}$ e $72 \%$ de NDT e abatidos com 30 a $32 \mathrm{~kg}$ de peso vivo. Substituindo-se o nível utilizado $(18 \% \mathrm{~PB})$ pelo autor acima, na equação de regressão ajustada no presente trabalho, estima-se rendimento verdadeiro de 54,4\%.

SIQUEIRA \& FERNANDES (1999) observaram médias de 47,53\%, para animais mestiços e $47,09 \%$, para animais puros terminados em confinamento, recebendo dieta com $15 \%$ de $\mathrm{PB}$ e $70 \%$ de NDT, abatidos com 30 a $32 \mathrm{~kg}$ de peso vivo. Substituindo-se o nível utilizado $(15 \% \mathrm{~PB})$ pelo autor acima, na equação de regressão ajustada no presente trabalho, estima-se rendimento verdadeiro de $55 \%$. 
Tabela 2 - Médias e erros-padrão para peso da carcaça quente (PCQ), peso da carcaça fria (PCF), rendimento comercial da carcaça (RCC), rendimento verdadeiro da carcaça (RVC), índice de compacidade da carcaça (ICC) e do pernil (ICP), condição corporal (CC), conformação (CO), cobertura de gordura (CBG), consistência da gordura (COB), cor da carne (CCA), área de olho de lombo (AOL) e espessura de gordura (ES), de acordo com os níveis protéicos na dieta e sexo.

\begin{tabular}{|c|c|c|c|c|}
\hline \multicolumn{5}{|c|}{ Níveis protéicos (\%PB) } \\
\hline Sexo & 12 & $\begin{array}{c}16 \\
\text { PCQ }(\%)\end{array}$ & 20 & 24 \\
\hline Machos & $18,52 \pm 0,3558$ & $18,52 \pm 0,3414$ & $18,31 \pm 0,3405$ & $18,65 \pm 0,3448$ \\
\hline Fêmeas & $18,59 \pm 0,3396$ & $\begin{array}{c}19,21 \pm 0,3410 \\
\text { PCF }(\%)\end{array}$ & $18,74 \pm 0,3394$ & $18,69 \pm 0,3397$ \\
\hline Machos & $17,97 \pm 0,3533$ & $18,07 \pm 0,3391$ & $17,74 \pm 0,3381$ & $18,19 \pm 0,3423$ \\
\hline Fêmeas & $17,77 \pm 0,3372$ & $\begin{array}{c}18,54 \pm 0,3386 \\
\text { RCC }(\%)\end{array}$ & $18,06 \pm 0,3370$ & $17,93 \pm 0,3373$ \\
\hline Machos & $48,01 \pm 0,0089$ & $48,37 \pm 0,0086$ & $47,62 \pm 0,0085$ & $48,75 \pm 0,0086$ \\
\hline Fêmeas & $47,72 \pm 0,0085$ & $\begin{array}{c}49,69 \pm 0,0085 \\
\operatorname{RCV}(\%)\end{array}$ & $48,21 \pm 0,0085$ & $48,08 \pm 0,0085$ \\
\hline Machos & $55,46 \pm 0,0106$ & $53,66 \pm 0,0102$ & $52,93 \pm 0,0101$ & $53,05 \pm 0,0103$ \\
\hline Fêmeas & $55,34 \pm 0,0101$ & $\begin{array}{c}56,27 \pm 0,0102 \\
\text { ICC }(\mathrm{kg} / \mathrm{cm})\end{array}$ & $54,93 \pm 0,0101$ & $54,01 \pm 0,0101$ \\
\hline Machos & $0,26 \pm 0,8562$ & $0,27 \pm 0,8216$ & $0,27 \pm 0,8192$ & $0,25 \pm 0,8295$ \\
\hline Fêmeas & $0,27 \pm 0,8171$ & $\begin{array}{c}0,29 \pm 0,8204 \\
\text { ICP }\end{array}$ & $0,27 \pm 0,8165$ & $0,27 \pm 0,8173$ \\
\hline Machos & $0,37 \pm 0,0395$ & $0,39 \pm 0,0379$ & $0,38 \pm 0,0378$ & $0,51 \pm 0,0383$ \\
\hline Fêmeas & $0,48 \pm 0,0377$ & $\begin{array}{c}0,46 \pm 0,0379 \\
\mathrm{CC}\end{array}$ & $0,43 \pm 0,0377$ & $0,43 \pm 0,0377$ \\
\hline Machos & $3,125 \pm 0,2394$ & $2,688 \pm 0,1197$ & $2,750 \pm 0,2500$ & $2,563 \pm 0,0494$ \\
\hline Fêmeas & $2,875 \pm 0,1250$ & $\begin{array}{c}3,000 \pm 0,2041 \\
\mathrm{CO}\end{array}$ & $3,125 \pm 0,2394$ & $2,875 \pm 0,1146$ \\
\hline Machos & $3,500 \pm 0,2041$ & $3,375 \pm 0,3146$ & $3,500 \pm 0,3536$ & $3,500 \pm 0,2887$ \\
\hline Fêmeas & $2,375 \pm 0,2394$ & $\begin{array}{c}3,875 \pm 0,2887 \\
\mathrm{CBG}\end{array}$ & $3,500 \pm 0,1250$ & $3,625 \pm 0,2394$ \\
\hline Machos & $3,500 \pm 0,2887$ & $3,375 \pm 0,2394$ & $3,250 \pm 0,1444$ & $3,250 \pm 0,3228$ \\
\hline Fêmeas & $3,750 \pm 0,1444$ & $\begin{array}{c}3,875 \pm 0,1250 \\
\text { COG }\end{array}$ & $3,750 \pm 0,1444$ & $3,875 \pm 0,1250$ \\
\hline Machos & $1,625 \pm 0,1250$ & $1,625 \pm 0,1250$ & $1,750 \pm 0,1444$ & $2,00 \pm 0,000$ \\
\hline Fêmeas & $1,750 \pm 0,1444$ & $\begin{array}{c}1,750 \pm 0,1444 \\
\mathrm{CCA}\end{array}$ & $1,625 \pm 0,1250$ & $1,750 \pm 0,1444$ \\
\hline Machos & $3,125 \pm 0,0722$ & $2,688 \pm 0,0722$ & $2,750 \pm 0,0722$ & $2,563 \pm 0,0625$ \\
\hline Fêmeas & $2,875 \pm 0,0625$ & $\begin{array}{c}3,000 \pm 0,0625 \\
\text { AOL }\end{array}$ & $3,125 \pm 0,0722$ & $2,875 \pm 0,0625$ \\
\hline Machos & $14,81 \pm 0,0746$ & $13,07 \pm 0,4658$ & $13,95 \pm 0,5675$ & $14,02 \pm 0,1764$ \\
\hline Fêmeas & $14,41 \pm 0,0746$ & $\begin{array}{c}13,95 \pm 0,4658 \\
\text { EG }\end{array}$ & $12,57 \pm 0,5676$ & $14,12 \pm 0,1764$ \\
\hline Machos & $2,13 \pm 0,7865$ & $3,04 \pm 0,7545$ & $2,42 \pm 0,7525$ & $3,43 \pm 0,7619$ \\
\hline Fêmeas & $4,71 \pm 0,7505$ & $4,41 \pm 0,7536$ & $6,67 \pm 0,7500$ & $4,86 \pm 0,7507$ \\
\hline
\end{tabular}

Cabe ressaltar que nem sempre as carcaças de maiores rendimentos são as melhores, devido, muitas vezes a um excessivo grau de gordura e/ou a uma idade e pesos elevados, aspectos negativos tanto sob o ponto de vista qualitativo como econômico (SAÑUDO \& SIERRA, 1982).

Não se observou efeito significativo $(\mathrm{P}>0,05)$ dos níveis protéicos sobre os índices de compacidade da carcaça. A média geral para esta variável foi de $0,271(\mathrm{~kg} / \mathrm{cm})$. O valor obtido por REIS (1999), para índice de compacidade da carcaça, foi de 0,209 (kg/cm) para animais abatidos, com média de 34kg de peso vivo. OSÓRIO et al. (1999) encontraram para cordeiros abatidos, com média de $30 \mathrm{~kg}$ de peso vivo, terminados em campo nativo, índice de compacidade da carcaça de $0,229(\mathrm{~kg} / \mathrm{cm})$. 
A análise de variância revelou efeito do peso corporal $(\mathrm{P}<0,05)$ sobre o índice de compacidade da carcaça, os quais foram superiores para as carcaças mais pesadas. Não se observou efeito significativo $(\mathrm{P}>0,05)$ para índice de compacidade da pernil (ICP), em função dos níveis de proteína. A média geral foi de 43,61, diferindo dos resultados encontrados por MACEDO (1998) e REIS (1999), de 48,4 e 45,75, respectivamente. A análise de variância não revelou efeito $(\mathrm{P}>0,05)$ de sexo para os índices de compacidade da carcaça e do pernil.

As análises de deviance não mostraram efeito significativo $(\mathrm{P}>0,05)$ dos níveis protéicos para condição corporal, conformação, cobertura de gordura, consistência da gordura e cor da carne. Com relação à condição corporal, a análise de deviance mostrou efeito significativo $(\mathrm{P}<0,01)$ de sexo, tendo as fêmeas apresentado escore médio de 2,97, contra 2,78 dos machos, valores estes, menores que os encontrados por MACEDO (1998) e SIQUEIRA \& FERNANDES (2000), de 3,13 e 2,63, respectivamente.

A condição corporal aumentou $(\mathrm{P}<0,05)$ de forma linear, à medida em que se elevou o peso corporal dos animais. Para conformação da carcaça, a análise de deviance mostrou diferença significativa $(\mathrm{P}<0,01)$ para peso corporal, tendo os animais com menor peso, apresentado conformação inferior. Não foi observado efeito $(\mathrm{P}>0,05)$ de sexo para esta variável. Os valores médios estimados para a conformação foram de 3,59 para as fêmeas e 3,46, para os machos.

SIQUEIRA \& FERNANDES (2000) encontraram valores de conformação da carcaça de 2,8 para cordeiros Corriedale x Ile de France, terminados em confinamento. Trabalhando com silagem de grãos úmidos de milho, REIS (1999) constatou valores de conformação de 2,75. Para cobertura de gordura, observou-se efeito significativo $(\mathrm{P}<0,05)$ do peso vivo, pois a elevação deste proporcionou carcaças com mais tecido adiposo. Foi observado também, efeito significativo para sexo, tendo as fêmeas apresentado maiores valores do que os machos. Segundo LEE et al. (1990), por causa da forte relação entre peso da carcaça e gordura de cobertura e a tendência das fêmeas apresentarem mais gordura a um determinado peso, elas devem ser enviadas para o abate a um peso inferior ao estipulado para os machos.

A cor da carne, de acordo com a análise de deviance, não se alterou $(\mathrm{P}>0,05)$ em função dos níveis protéicos, apresentando-se, em média, mais próxima da cor rósea $(1,37)$, resultado similar ao constatado por JONES et al. (1984). Observou-se efeito significativo $(\mathrm{P}<0,01)$ do peso vivo, sobre a cor da carne, sendo que os animais com maior peso apresentaram cor da carne mais escura. Não foi observado efeito de sexo $(\mathrm{P}>0,05)$ para esta variável. REIS (1999), analisando cordeiros terminados com silagem de milho em diferentes formas, os quais receberam dietas isoprotéicas $(20 \% \mathrm{~PB})$, com abate dos animais em diferentes pesos, observou que o maior peso de abate resultou em uma carne mais escura.

$\mathrm{O}$ peso corporal apresentou efeito linear sobre a área de olho de lombo $(\mathrm{P}<0,01)$. A análise de variância revelou efeito quadrático $(\mathrm{P}=0,053)$ do nível crescente de proteína bruta na dieta sobre área de olho de lombo, sendo $\hat{Y}=24,0779-1,1649 \mathrm{x}+0,03118183 \mathrm{x}^{2}$, a equação de regressão ajustada. Nầo foi observado efeito de sexo $(\mathrm{P}>0,05)$ para área de olho de lombo, sendo a média geral para esta variável igual a 13, 84 $\mathrm{cm}^{2}$. Este comportamento quadrático, com ponto de mínimo em 18,68\%, deve ser considerado com reservas, visto que não se enquadra dentro de padrões biologicamente explicáveis. BONA FILHO et al. (1992), tendo terminado cordeiros em confinamento, suplementados com diferentes níveis de farinha de peixe, em substituição ao farelo de soja, encontraram área de olho de lombo de $14,35 \mathrm{~cm}^{2}$, para animais recebendo dieta com $18 \%$ de $\mathrm{PB}$ e $75 \%$ de NDT. Os resultados referentes à área de olho de lombo, encontrados por BUENO et al. (1998), trabalhando com dieta contendo $20 \%$ de PB, foram 11,5 e $13,2 \mathrm{~cm}^{2}$, para cordeiros machos e fêmeas, respectivamente, abatidos com peso médio de $30,9 \mathrm{~kg}$, valores estes inferiores ao presente estudo. OSÓRIO et al. (1999) observou áreas de 10,2 e 11,99, para cordeiros castrados e inteiros, respectivamente, abatidos com 5 meses de idade, criados em condições extensivas de campo nativo. SILVA \& PIRES (2000) encontraram valores de 10,97 e 11,00 para pesos de abate de 28 e $30 \mathrm{~kg}$, respectivamente.

Em relação à espessura de gordura no Longissimus dorsi, a análise de variância não revelou efeito significativo $(\mathrm{P}>0,05)$ dos níveis protéicos. A média encontrada para esta variável foi de $3,83 \mathrm{~mm}$. Houve efeito significativo de sexo $(\mathrm{P}<0,05)$, tendo as fêmeas apresentado médias de 4,91 mm e os machos 2,76 mm. Segundo SAINZ (1996), com o aumento da idade e do peso, a proporção de gordura na carcaça aumenta ainda mais rapidamente.

Os resultados verificados para espessura de gordura, por BUENO et al. (1998), foram de 1,2 e 1,9 $\mathrm{mm}$ para machos inteiros e fêmeas da raça Suffolk , abatidos com peso médio de $31,7 \mathrm{~kg}$, recebendo dieta com $20 \%$ PB. SILVA et al. (1998), encontraram valores de $1,75 \mathrm{~mm}$ para animais abatidos com peso médio de $28 \mathrm{~kg}$ e 1,42mm, para $33 \mathrm{~kg}$ de peso vivo. PÉREZ et al. (1998) verificaram valores de 2,74 e $3,24 \mathrm{~mm}$, para cordeiros das raças Santa Inês e Bergamácia, recebendo 
rações com $18 \%$ de PB e abatidos com 53,43 e 52,86 kg de peso corporal, respectivamente. Foi observado efeito linear significativo $(\mathrm{P}<0,01)$ do peso corporal sobre a deposição de proteína no músculo Semitendinosus. A análise de variância para deposição de proteína revelou efeito da interação entre tratamento e sexo $(\mathrm{P}<0,01)$, ajustando, assim, diferentes equações para cada um dos sexos. A média estimada de proteína depositada no músculo Semitendinosus foi de 19,84\%.

A equação de regressão $\hat{Y}=-63,73+7,497 \mathrm{~N}$ 0,1529N ${ }^{2}+1,035 \mathrm{PVI}-0,0803 \mathrm{NxPVI}$ ) para machos mostra pela derivação $\mathrm{dY} / \mathrm{dN}$, ponto de máximo de $16,64 \%$ de $\mathrm{PB}$, para peso vivo inicial de $30 \mathrm{~kg}$. Isto significa que, com $16,64 \%$ de proteína dietética, alcançou-se maior deposição de proteína muscular nos machos. A equação de regressão $\hat{Y}=51,25-4,702 \mathrm{~N}+0,1384 \mathrm{~N}^{2}$ 0,4298PVI) para fêmeas, mostra pela derivação $\mathrm{dY} / \mathrm{dN}$, ponto de mínimo de $16,99 \%$ de $\mathrm{PB}$, para peso vivo inicial de $30 \mathrm{~kg}$. Este comportamento se assemelha àquele apresentado para área de olho de lombo, fora dos padrões biológicos, devendo, portanto, ser considerado com reservas. Trabalhos encontrados na literatura, tais como o de MURPHY et al. (1994) e MACEDO (1998), estudaram o teor de proteína no músculo Longissimus dorsi, diferentemente do que foi estudado neste trabalho, em que se analisou a deposição de proteína no músculo Semitendinosus. Não foram observados efeitos significativos $(\mathrm{P}>0,05)$ para esta variável, indicando não haver efeito dos níveis de proteína da dieta.

\section{CONCLUSÕES}

Em virtude da idade dos cordeiros acima de 5 meses, os níveis protéicos não influenciam as características de carcaça estudadas, sugerindo que o menor nível utilizado $(12 \% \mathrm{~PB})$ atende às necessidades nutricionais dos animais. Exceção se faz ao rendimento verdadeiro de carcaça, que é superior ao nível de $12 \%$ de proteína bruta.

\section{REFERÊNCIAS BIBLIOGRÁFICAS}

BONA FILHO, A.F. et al. Ganho de peso e características de carcaça de cordeiros confinados e suplementados com diferentes níveis de farinha de peixe. Agrárias, v.13, n.1, p.183-191, 1992 .

BUENO, M.S. et al. Avaliação de carcaças de cordeiros Suffolk abatidos com diferentes pesos vivos. In: REUNIÃO ANUAL DA SOCIEDADE BRASILEIRA DE ZOOTECNIA, 35, 1998, Botucatu, SP. Anais... Botucatu : SBZ, 1998, Cd rom-RUM268.

COLOMER-ROCHER, F. Estudio de los parametros que definen los caracteres cuantitativos y cualitativos de las canales. In:
CURSO INTERNACIONAL SOBRE PRODUCCIÓN DE CARNE Y LECHE CON BASES EN PASTOS Y FORRAJES,1, 1988. La Coruña, Espanha, 1988. 108p.

EUCLYDES, R.F. Manual de utilização do programa SAEG - SISTEMA PARA ANÁLISES ESTATÍSTICAS E GENÉTICAS. 1993. V içosa, MG : UFV/CPD, 1993. 59p.

FERNANDES, S. Peso vivo ao abate e características da carcaça de cordeiros da raça Corriedale e mestiços Ile 1994. 82f. Dissertação (Mestrado em Zootecnia) - Curso de Pós-graduação em Zootecnia, Universidade Estadual Paulista.

FOLCH, J.; LEES, M.; MORTON, M.L. A simple method for the isolation and purification of total lipides from animal tissues. J Biol Chem, v.22, n.6, p.497-509, 1957.

JARRIGE, R. Alimentação dos bovinos, ovinos e caprinos. Men Mmartins : Europa- América Latina, 1988. 460p.

JONES, S.D.M., et al. The growth performance and carcass composition of ram and ewe lambs fed on pasture or in confinement and slaughtered at similar fatness. Can J Anim Sci, v.64, p. 631-640. 1984.

JORGE, A.M. et al. Desempenho produtivo de animais de quatro raças zebuínas abatidos em três estágios de maturidade. 2. Características da carcaça. R Bras Zootec, v. 28, n.2, p.381387, 1999.

LEE,G.J. et al. Growth and carcass fatness of ewe, whether, ram and cryptorchid crossbred lambs reared at pasture: effects of weaning age. Austr J Exp Agric, v.30, p.743$747,1990$.

MACEDO, F.A.F. Desempenho e características de carcaças de cordeiros Corriedale mestiços Bergamácia $x$ Corriedale e Hampshire Down $x$ Corriedale, terminados em pastagem e confinamento. 1998. $72 \mathrm{f}$. Tese (Doutorado em Zootecnia) - Curso de Pós-graduação em Zootecnia, Faculdade de Medicina Veterinária e Zootecnia/ UNESP.

McCULLCOH, C.E.; SEARLE, S. Generalized, linear and mixed models. New York : John Wiley e Sons, 2001. $325 \mathrm{p}$.

MURFHY, T.A; LOERCH, S.C.; McCLURE, K.E. Effects of grain or pature finishing systems on carcass composition and tissue accretion rates of lambs. J Anim Sci, v.72, p.3230$3270,1994$.

OSÓRIO, J.C.S. et al. Produção de carne entre cordeiros castrados e não castrados. I. Cruzas Hampshire Down x Corriedale. Ciência Rural, v.29,n.1, p.135-138, 1999.

OSÓRIO, J.C.S. Estudio de la calidad de canales comercializadas en el tipo Ternasco segun la procedencia: bases para la mejora de dicha calidad en Brasil. 1992. 335f. Tese (Doutorado em Veterinária)- Facultad de Veterinária, Universidad de Zaragoza.

PEREZ, J.R.O. et al. Desempenho de cordeiros Santa Inês e Bergamácia alimentados com diferentes níveis de dejetos de suínos. In: REUNIÃO ANUAL DA SOCIEDADE BRASILEIRA DE ZOOTECNIA, 35., 1998. Botucatu-SP. Anais... Botucatu, SP : SBZ, 1998. Cd room-RM230. 
REIS, W. Desempenho e características de carcaça de cordeiros alimentados com dietas contendo grãos de milho conservados em diferentes formas. 1999. $48 \mathrm{f}$. Dissertação (Mestrado em Zootecnia) - Curso de Pós-graduação em Zootecnia, Universidade Estadual de Maringá.

SAINZ, R.D. Qualidade das carcaças e da carne ovina e caprina. In: SIMPÓSIO DA REUNIÃO ANUAL DA SOCIEDADE BRASILEIRA DE ZOOTECNIA, 33., 1996, Fortaleza-CE. Anais... Fortaleza-CE : SBZ, 1996. p.3-4 .

SAÑUDO, C.; SIERRA, I. Estudio de la calidad de la canal y de la carne en animales cruzados Romanov por Rasa Aragonesa. 2. Descripción y comparación entre los tipos ternascos y pascual. In: ANALES DE LA FACULTAD DE VETERINARIA DE ZARAGOZA, 1982, Zaragoza, Espaha. Anais... Zaragoza, 1982, p.285-295.

SAÑUDO, C.; SIERRA, I. Calidad de la canal en la especie ovina. Ovino. v.11, p.127-57,1986.
SILVA, L.F. et al. Estudo da composição e características da carcaça de cordeiros. In: REUNIÃO ANUAL DA SOCIEDADE BRASILEIRA DE ZOOTECNIA, 35., 1998, Botucatu-SP. Anais... Botucatu, SP : SBZ, 1998. Cd room-RUM197.

SILVA, L.F.; PIRES, C.C. Avaliações quantitativas das proporções de osso, músculo e gordura da carcaça em ovinos. Rev Bras Zootec, v.29, n.4, p.1253-1260, 2000.

SIQUEIRA, E.R.; FERNANDES, S. Efeito do genótipo sobre as medidas objetivas e subjetivas da carcaça de cordeiros terminados em confinamento. R Bras Zootec, v.29, n.1, p.306311,2000 .

SIQUEIRA, E.R.; FERNANDES, S. Pesos, rendimentos e perdas da carcaça de cordeiros Corriedale e mestiços Ile de France e Corriedale, terminados em confinamento. Ciência Rural, v.29, n.1, p.143-148, 1999.

TEIXEIRA, A.; DELFA, R.; GONCALEZ, C. El grado de engrasamiento. Rev Ovis, v.19, p.21-35, 1992. 